\title{
DATAÇÕES DE GRAVURAS RUPESTRES NO BRASIL: Pesquisa e Métodos Arqueológicos
}

\section{ROCK ENGRAVING DATES IN BRAZIL: methods and archaelogical research}

\author{
Daline Lima de Oliveira ${ }^{1}$ \\ daline.bs@hotmail.com \\ Valdeci dos Santos Júnior ${ }^{2}$ \\ valdecisantosjr@hotmail.com
}

\section{RESUMO}

Este artigo tem como objetivo evidenciar os métodos atualmente utilizados para obter datações relacionadas às gravuras rupestres, elaborando um quadro das pesquisas arqueológicas, tanto em nível mundial, como em nível de Brasil, voltadas para a obtenção de cronologias provenientes das ocupações humanas pretéritas que se dedicaram as criações simbólicas gravadas. Os resultados das pesquisas já efetuadas de datações com gravuras rupestres no Brasil indicam ocupações no período holocênico e persistência temporal com essa técnica de execução no mesmo suporte rochoso, além da reutilização, através de reavivamentos nas mesmas simbologias, por grupos gráficos posteriores.

Palavras chaves: Métodos de datações, gravuras rupestres, cronologias.

\footnotetext{
${ }^{1}$ Discente, Programa de Pós-graduação em Arqueologia, UFPI.

${ }^{2}$ Departamento de História, UERN.
} 


\begin{abstract}
This article aims to highlight the methods currently used to obtain dates related to rock engravings, elaborating a framework of archaeological research, both at the world level and at the Brazilian level, aimed at obtaining chronologies from the previous human occupations that were dedicated the engraved symbolic creations. The results of the researches already done with rock engraving dates in Brazil indicate occupations in the Holocene period and temporal persistence with this technique of execution in the same rocky support, besides the reutilization, through revivals in the same symbologies, by later graphic groups.
\end{abstract}

Keywords: Methods of dating, rock engravings, chronologies.

\title{
CONTEXTO DA PESQUISA
}

As pesquisas em arqueologia no Brasil vêm se ampliando bastante nas duas últimas décadas e no Nordeste Brasileiro, onde uma boa parte das pesquisas está voltada para os registros rupestres, principalmente os estudos direcionados para a técnica de pinturas. Os sítios arqueológicos da Serra da Capivara, no Sudeste do Piauí; da Serra do Araripe, no Ceará; do Vale do Catimbau, em Pernambuco; da Região Central da Bahia e da região do Seridó do Estado do Rio Grande do Norte, foram algumas das áreas pesquisadas nesses estudos, (ETCHEVARNE, 2007; PESSIS, 2003; MARTIN, 1997).

Entre outros objetivos dessas pesquisas, um deles era obter dados cronológicos sobre a elaboração dos grafismos pintados; na área da Serra da Capivara, no Sudeste do Piauí, por exemplo, foi possível obter datações indiretas dessas pinturas por associações estratigráficas com níveis sedimentares, tendo em vista a 
quantidade expressiva de escavações realizadas em diversos abrigos e semiabrigos desde á década de 70 do século XX, permitindo estabelecer um quadro cronológico de ocupações para elaborações rupestres pintadas de 12000 a 6000 BP, (GUIDON E PESSIS, 2000).

Mas a obtenção desses dados cronológicos não é tão fácil e se isso ocorre com grau de dificuldade nos sítios com os registros pintados pesquisados há décadas, essa dificuldade aumenta ainda mais com os registros gravados; basta observar pela pequena quantidade de pesquisadores que se dedicam com maior intensidade ao estudo das gravuras rupestres no Brasil ${ }^{3}$. A ausência frequente de recursos financeiros para pesquisas científicas pelos órgãos de fomento dificulta ainda mais esse quadro, fazendo com que o Brasil possua um campo vasto de sítios arqueológicos ainda totalmente inexplorados em termos de datações. Esse artigo irá abordar sobre os métodos de datações atualmente existentes para os registros rupestres (com ênfase na técnica de gravuras) e as pesquisas com datações efetuadas em sítios arqueológicos com gravuras rupestres no Brasil.

\footnotetext{
${ }^{3}$ Atualmente (2019) no Brasil são poucos pesquisadores com que estudaram especificamente as gravuras rupestres com teses de doutorados, entre os quais podem ser mencionados: Fabiana Commerlato com a tese de doutorado defendida em 2005 "As representações rupestres do litoral de Santa Catarina"; Raoni Valle, com a tese de doutorado defendida em 2012 "Mentes graníticas e mentes areníticas: fronteira geo-cognitiva nas gravuras rupestres do baixo Rio Negro, Amazônia Setentrional"; Welington Lage, com a tese de doutorado "Por entre rochedos bordados passa um rio: um olhar da Gestalt para efetuar uma leitura do passado" defendida em 2018 (nota do autor).
} 


\section{OS MÉTODOS DE DATAÇÕES APLICADOS NOS REGISTROS RUPESTRES}

Segundo Prous (1989a), há alguns procedimentos que podem ser aplicados ou inferências para se datar os registros rupestres, a depender do contexto do sítio arqueológico, onde as datações podem ser "relativas", "absolutas" ou "semiabsolutas". Para ele, as datações relativas são aquelas que permitem que possa ser estabelecida uma ordem de antiguidade em relação aos registros rupestres, porém sem a determinação de uma datação precisa, implicando tão somente em uma sequência de antiguidade; já a datação absoluta ou semiabsoluta permite que se possa estabelecer uma data mínima ou máxima para as criações gráficas a serem analisadas.

Para esse pesquisador, uma das formas de se obter datações semi absolutas é mediante a análise temática específica que sirva como marco comparativo, a exemplo de um fóssil guia. Este pode servir como parâmetro para suposição, por exemplo, de que o autor do registro conviveu com uma fauna já extinta. O parâmetro também pode ser outra representação gráfica que indique um "momento cronológico guia", digamos assim, como referências de plantas, atividades de cultivos ou observações astronômicas, onde ele considera que as datações absolutas são apenas presumidas. Outras possibilidades de se realizar datação absoluta em registros rupestres podem ser através da datação de pigmentos, quando estes contiverem em sua composição elementos orgânicos, que favoreçam a datação por carbono 14-C; outros métodos de datação podem ser 
obtidos por racemização ou por cromatografia dos aminoácidos, considerando que a composição dos pigmentos carregue proteínas, ou seja, também envolvendo a presença de pigmentos orgânicos, (PROUS, 1986b).

Já em relação às datações diretas, Prous, (1986b) menciona uma das técnicas que pode ser aplicada denominada Espectroscopia de Ressonância Paramagnética Eletrônica (ESR), sendo chamada também de Ressonância de Spin Eletrônico (ESR). Sua aplicação pode destinar-se a datar urânio associado à calcita, presente nas camadas que se formam sobre as pinturas, que são comuns em sítios rupestres de regiões calcárias. Tais películas também podem ser datadas por 14-C; ele se refere também a outro método que pode ser utilizado nesse mesmo contexto: a Espectroscopia de Massa.

Dorn (2000) considera que o acelerador de espectrometria de massa (AMS) para a datação de radiocarbono (14-C) foi um grande marco para a datação dos registros rupestres, sobretudo por exigir miligramas de material de carbono orgânico para que se obtenha datações, no caso da presença deste em pigmentos de pictogramas, por exemplo; ou mesmo em revestimentos naturais na rocha, no caso de gravuras ou geóglifos. No entanto, ele evidencia um aspecto importante em relação à matéria orgânica presente em pigmentos ou em revestimento de gravuras ou geóglifos: trata-se da questão da não identificação da natureza da matéria orgânica e de sua preexistência, no caso do pigmento, e, quanto as gravuras e geóglifos, a distância cronológica. Ele discute a possibilidade de utilização de "plasma 
químico seletivo" para a identificação de carbono orgânico em pigmentos, que é um método de remoção não destrutivo, e que pode ser extraído de carbonos contidos em carbonato de cálcio, oxalato e carbonato de magnésio, para datar pigmentos.

Um dos pesquisadores mais dedicados atualmente à datação em registros rupestres é o austríaco Robert Bednarik, que defende os métodos de datações como fatores fundamentais na elaboração de construções arqueológicas, sendo um pouco reticente quanto às análises estilísticas e iconográficas. Quanto à abordagem iconográfica, por exemplo, ele observa que este tipo de estudo ao tentar correlacionar alguns motivos com achados arqueológicos, também poderá conduzir a inferências de representações cerimoniais. Ele reconhece a relevância desta abordagem, mas chama a atenção que o seu uso em demasiado pode levar a erros de avaliação por não levar em conta as estratégias cognitivas dos produtores dos registros rupestres, uma vez que pode não ter qualquer correspondência com as de seus intérpretes ou observadores atuais, (BEDNARIK, 2002).

Um dos métodos mais utilizados de se conseguir datações com cronologia mínima de sua elaboração ou contemporaneidade de uma pintura ou gravura em um painel gráfico, pode ser obtido por acréscimos sedimentares, ou seja, quando se consegue material que pode ser datado em escavações (como restos de carvões derivados de fogueiras antrópicas, por exemplo), cujos sedimentos se superponham diretamente aos vestígios culturais; entretanto, é preciso que a origem dos sedimentos não 
tenha sofrido perturbação estratigráfica, como, por exemplo, eventuais transformações geomorfológicas.

\section{Os métodos de datações em gravuras rupestres}

Um procedimento metodológico utilizado para estimar a datação das gravuras rupestres é a análise microscópica das alterações na superfície da rocha, estando voltado para o estudo da formação da pátina nos painéis com gravuras, assim como o seu processo intempérico. As alterações nessa superfície rochosa podem ser redutivas, aditivas ou transformacionais, onde as alterações redutivas estão relacionadas à perda de massa, motivada, por exemplo, por erosão; as alterações com acréscimos estão associadas à adição de massa e as alterações transformacionais são ocasionadas por modificações químicas ou físicas, (BEDNARIK, 1992).

As principais dificuldades para os estudos desses processos para as datações de gravuras estão relacionadas, principalmente, as possíveis variações climáticas e topográficas durante a formação da pátina nessa superfície rochosa e das propriedades petrológicas do próprio suporte rochoso; são fatores naturais que dificultam a estimativa de datação mediante a análise, tais como os processos de repatinação, que estão relacionados diretamente as gravuras e que são utilizados como fonte de inferência de datação, (DORN, 2000). 
As acreções sobre as gravuras rupestres (que contenham partículas de resíduos orgânicos, contendo pólen, esporos, resíduos de algas mortas e outros microrganismos) podem proporcionar material para datação radiocarbônica. No entanto, os cuidados para a aplicação do método de datação por carbono 14-C nesse tipo de acreção, requerem rígidos estudos e análise para não gerar distorções nos resultados; em geral a análise de carbono 14-C de inclusões carbonáceas em acreções deve ser utilizada com cautela, devendo-se atentar principalmente para a descontaminação do carbono, (BEDNARIK, 2002).

No caso das acreções, uma das técnicas utilizadas é a datação por LOE (Luminescência Oticamente Estimulada) que pode ser aplicada as gravuras rupestres em dadas circunstâncias, ou seja, podem ser datados os sedimentos arqueológicos que foram depositados (acréscimos) naturalmente sobre os suportes rochosos contendo as gravuras. O que fundamenta esse método nos sedimentos minerais é que eles estão continuamente submetidos às radiações ionizantes, cujas fontes são os raios cósmicos e os radioisótopos presentes no solo, (MAIA et al., 2011).

Uma técnica de datação que verifica acréscimos minerais com material orgânico no suporte rochoso está relacionada aos revestimentos naturais de oxalato de cálcio, que por vezes, se desenvolvem nos sulcos das gravuras, onde o carbono neste mineral pode ser datado por carbono 14-C, proporcionando assim um mínimo de limitação de idade para as gravuras. Esta técnica assume que o carbono 
proveniente, por exemplo, do roçar contínuo de pele de animais, passa a fazer parte também do verniz mineral, sendo contemporâneo com o próprio verniz, ou seja, não incorpora carbono mais antigo do que o do próprio verniz. A aplicação desse método pode ser realizada também a partir de uma camada secundária formada a partir da precipitação da calcita em gravuras; a sua aplicação, no entanto, nesses casos, exige um amplo e aprofundado estudo de sua formação a fim de evitar equívocos interpretativos de seu resultado, (WATCHMAN, 2000). Outro método de datação direta é a liquenometria que se trata de um tipo de datação de idade calibrada, que busca obter uma idade mínima para superfícies de rochas a partir de parâmetros de crescimento dos líquens. Sabe-se que a taxa de crescimento destes está relacionada às condições geográficas, sendo necessário, portanto estabelecer uma taxa de crescimento de uma dada espécie para cada área; além do mais, outros fatores também interferem nessa taxa de crescimento, como a litologia e a exposição, (DUMONT et al., 2013).

A formação da pátina também é outro aspecto que pode ser estudada para se efetuar datações. Ela decorre de um revestimento natural, fino, derivado de partículas de argila em tamanho de poeira trazida pelo vento, que é fixado por micróbios da superfície rochosa. Os fatores químicos produzem alterações significativas na superfície rochosa ao longo do tempo, criando laminações microestratigráficas, cuja morfologia é determinada pelos regimes climáticos regionais e pode agregar partículas de matéria orgânica. Cada uma destas condições fornece uma possibilidade para análise cronométrica e controle de 
idade, onde essa pátina rochosa, se devidamente analisada, oferece potencial para que venha a se obter datação das gravuras, pela possibilidade de retenção de matéria orgânica. Estudos aprofundados sobre pátinas rochosas, com a realização de microlaminações e utilização de escalas, efetuados em diferentes contextos geoambientais, são ideais para ter um quadro que relacione o meio ambiente e rocha, inclusive possíveis mudanças no Quaternário, além de se obter datações mais confiáveis dessas pátinas (DORN, 2004; WHITLEY, et al., 2005).

\section{O método da datação direta por microerosão em gravuras.}

Uma técnica de datação direta que vem sendo aplicada para as gravuras rupestres pelo pesquisador Robert Bednarik e por pesquisadores chineses, é a análise visual de microerosão através das reduções efetuadas diretamente pelo intemperismo nas gravuras. Essa análise é realizada a partir do exame da nova superfície rochosa que, após ter sido produzida por agentes naturais ou antrópicos, ao longo do tempo (efeitos cumulativos) e que recebeu ações químicas e físicas que provocaram seu desgaste, (JIN A., ZHANG J., XIAO B. and TANG H. 2016; TANG H., G. KUMAR, LIU W., XIAO B., YANG H., ZHANG J., Lu X. H., YUE J., LI Y., GAO W. and R. G. BEDNARIK, 2017; BEDNARIK, 1992).

Bednarik (2002) explica que a análise de microerosão é um conjunto de métodos aplicado para datar diretamente as gravuras em rochas resistentes à erosão, tais como os granitos, mas que não pode ser realizado em rochas sedimentares. Ele cita dois critérios metodológicos que são utilizados: o que leva em conta a 
medição da taxa de declínio de cristais fraturados e a análise da perda seletiva por intemperismos físico-químicos de dados componentes de rocha em relação ao meio ambiente. Ele continua em sua explanação que, além do mais, as condições para a aplicação do método de datação por microerosão devem ser bastante rígidas, sendo necessários alguns requisitos para o sucesso na aplicação do método, entre os quais dois requisitos básicos: a possibilidade de calibração com um local com gravura de data já conhecida e a sua aplicação em suportes petrológicos de rochas graníticas, onde se obtém resultados mais confiáveis.

O pressuposto básico do método da microerosão é de que a intempérie progressiva ocorre em cristais originalmente fraturados durante a elaboração das gravuras e a taxa de desgaste pode ser calibrada em gravuras do mesmo sítio arqueológico (ou de sítios próximos com o mesmo tipo de suporte rochoso) que tenham uma data já conhecida; o método analisa esse intemperismo progressivo através da observação geométrica das partículas de quartzo do suporte granítico que sofreram arredondamento das bordas de rocha recém-quebradas, que são intituladas de "micro-wanes", (BEDNARIK, 2001).

Bednarik (1992, 2007) estabeleceu uma fórmula com dados geométricos e matemáticos (figura 1) a partir da diminuição progressiva do tamanho dessas partículas durante um determinado intervalo de tempo, conforme pode ser visto nas fórmulas das figuras 1 e 2 . 


$$
x=\sqrt{\left[\left(\frac{z}{\tan 0.5 \alpha}\right)^{2}+z^{2}\right]}
$$

Figura 1: Relação $x$ : $z$ é uma função de $\alpha$, e em $\alpha=60^{\circ}, \mathrm{x}=2 \mathrm{z}$. Fonte: Bednarik, 2007, p.130. O raio de rocha diminui (estritamente falando não é equicircular na seção, mas hiperbólico) em qualquer magnitude de tamanho, aumentando em função da idade. Durante o processo de diminuição, a razão $h$ : $r$ é constante para qualquer ângulo $\alpha$, independentemente da distância de recuo das faces e da aresta. Relação x: z é uma função de $\alpha$, e em $\alpha=60^{\circ}$, x $=2 \mathrm{z}$.

Isto leva à predição de $\beta$ o ângulo que expressa a taxa de desenvolvimento de diminuição em relação ao recuo de superfície, (figura 2).

$$
\beta=2 \sin ^{-1}\left(\frac{r}{x+h+r}\right)
$$

Figura 2: Fórmula para $\beta$. Fonte: Bednarik, 2007, p.130.

Assim, a relação da largura A diminui com a idade, independentemente do retrocesso factual, e é determinada, em última instância, pela relação $\alpha$ : $\beta$, que deve ser estabelecida empiricamente. Segue-se que as dimensões A, r, z e os ângulos $\alpha$ e $\beta$ estão todos relacionados geometricamente e algebricamente, e que as variáveis $\mathrm{A}, \mathrm{r}, \mathrm{x}, \mathrm{z}$ e $\mathrm{h}$ são todas proporcionalmente equivalentes e aumentam linearmente com a idade (figura 3). Destes, A é mais facilmente medido fisicamente. É, portanto, a variável utilizada na medição de micro-wane, (BEDNARIK, 2007, p.130). 


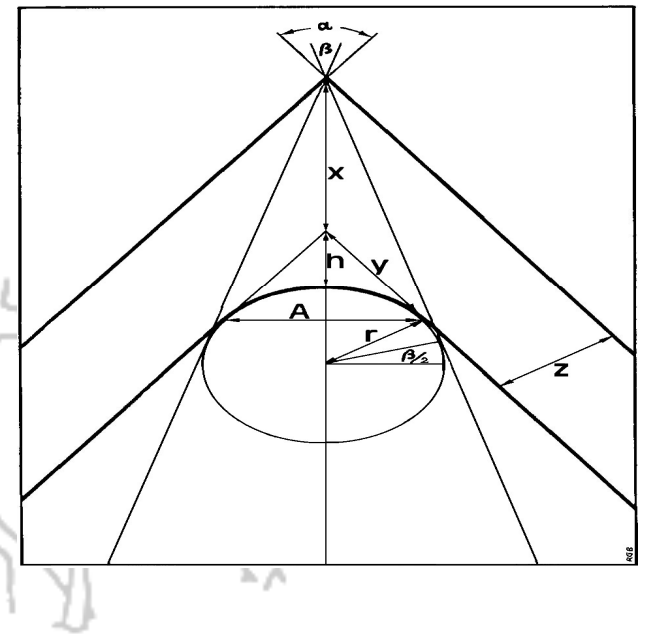

Figura 3: Diagrama que descreve as leis da formação da diminuição (wane) em uma forma simplificada. Fonte: Bednarik, 2007, p. 130 .

\section{A aplicação do método direto da microerosão no mundo.}

O método da microerosão foi testado em sítios arqueológicos de vários países. Ao aplicar o método em gravuras rupestres do sítio Inca Huasi, na bacia do Rio Mizque, na Bolívia, Bednarik conseguiu obter uma série de datações permitindo estabelecer uma sequência cronológica de etapas diferenciadas de gravuras elaboradas que vão desde o final do Pleistoceno ou início do Holoceno (10.0007.000 anos BP); tendo uma segunda etapa de execução entre 4.000 e 1.500 anos BP; e finalmente uma terceira etapa situada entre 1.330 e 730 anos B.P. (BEDNARIK, 2000). Em Valtellina, nos Alpes italianos, Bednarik (2001) obteve datações variáveis entre 6.000 a 3.000 BP para as gravuras que estavam condizentes com as cronologias defendidas por outros arqueólogos (ANATI, 1994; FOSSATI, 1995).

Apesar da utilização com sucesso em várias regiões, o método da microerosão também recebeu críticas de pesquisadores. Dorn (1997) alertou que os 
revestimentos de suporte rochoso (repatinação) em que são elaboradas as gravuras ocorrem em todos os ambientes de intemperismos terrestres, exceto os motivos que estão corroendo rápido demais para que eles desenvolvam; isto significa que a coleta de dados da microerosão é aplicável apenas em lugares onde as gravuras são demasiadas recentes (geralmente menos de alguns milhares de anos) para que um revestimento com pátina possa se formar.

Ao aplicar o método da microerosão nos petróglifos do Vale do Côa, em Portugal, Bednarik obteve resultados cronológicos que apontavam para criações simbólicas efetuadas no Holoceno médio, (entre 7.000 a 6.000 AP), descartando qualquer possibilidade de elaboração (das gravuras que foram examinadas por ele) de pertencerem ao Pleistoceno. Seus dados temporais foram depois corroborados por outros pesquisadores, tais como Alan Watchman (1995) e Ronald Dorn (1997), que utilizaram outros métodos de datação com carbono 14-C e 36-C, (BEDNARIK, 1995).

A aplicação deste método em sítios arqueológicos do Vale do Côa, em Portugal, foi criticada pelo arqueólogo português Antônio Soares, que observou que os requisitos básicos para a sua utilização não foram cumpridos, gerando assim datações com resultados sem "qualquer fiabilidade"; ele alegou que as datações obtidas no Côa através do método de microerosão teriam sido feitas sem a devida calibração, além de terem sido realizadas em xistos e que, embora existissem sítios arqueológicos em granito no Côa, ele fala que Bednarik alegou "a falta de 
tempo" para acessar estes sítios, afirmando também que a maioria das rochas do Côa são xistos metamorfizados, com esfoliações (SOARES, 1995, p. 501).

Soares (1995) continuou alegando que, não obstante tenham sido aplicados outros métodos de datação no Vale do Côa, como as datações por carbono 14-C e 36-C, há restrições em relação à aplicação destes métodos, como a possível descontaminação do carbono, por exemplo, cujos resultados podem deixar margem a questionamentos; para ele nesse sentido, restou a datação por carbono 14-C em certos contextos e a análise estilística como opções de resultados de interpretação temporais mais confiáveis. Posição, aliás, também defendida pelo pesquisador português João Zilhão, que atribui críticas às datações diretas pelo método da microerosão obtidas por Bednarik, assim como às datações indiretas obtidas por Dorn e Watchman, (ZILHÃO, 1995, 2004).

Portanto, a respeito dos questionamentos que foram empreendidos (como ocorre em qualquer método que envolva diversas variáveis), a utilização do conjunto de procedimentos de análise através da microerosão das gravuras em suportes graníticos deve ser usada com cautela acadêmica e procurando seguir todos os critérios metodológicos, para que se possam obter datações e, posteriormente, compará-las cronologicamente com outras datações obtidas por outros métodos diretos ou indiretos. 


\section{AS DATAÇÕES INDIRETAS DE GRAVURAS RUPESTRES NO BRASIL}

No Brasil foram feitas algumas tentativas de datação de gravuras rupestres com métodos indiretos. A mais antiga dessas datações indiretas (relativas) de gravuras, talvez das Américas até agora, foi obtida numa escavação arqueológica, a $4 \mathrm{~m}$ de profundidade, na Lapa do Santo, um abrigo calcário localizado em Lagoa Santa, Estado de Minas Gerais. Foram datados grãos de quartzo pelo método da termoluminescência (LOE) em sedimentos situados em níveis estratigráficos abaixo e acima das gravuras realizadas no suporte rochoso do abrigo que delimitaram um intervalo cronológico provável de execução situado entre 11.760 BP a 9.960 BP, (NEVES et al., 2012).

O pesquisador Raoni Valle ao escavar em 2014 o sítio arqueológico Pedra do Sol que possui gravuras rupestres, localizado no município de São Luís do Anauá, no SE do Estado de Roraima, na região Norte do Brasil, efetuou datações de fogueiras antrópicas associadas com sedimentos, levantando hipóteses relacionadas as possíveis correlações com a elaboração das práticas gráficas:

Desta forma, hoje é possível sugerir um cenário de associações incipientes e em caráter conjetural entre o evento de combustão mais antigo identificado há 9.400 anos antes do presente e as gravuras mais antigas da Parede NE, sobretudo os geométricos verticais e as cúpulas, significativamente mais intemperizados dentro do conjunto. Por conseguinte, também se sugere que o evento de combustão datado no sítio de 4.000 anos antes do presente pode estar associado às gravuras preliminarmente identificadas como do segundo perfil gráfico do sítio. (VALLE, 2017, p. 23). 
Outra datação indireta de gravuras obtida foi no sítio Toca dos Oitenta, no Parque Nacional da Serra da Capivara, em São Raimundo Nonato, Estado do Piauí, no Nordeste brasileiro. Através da datação radiocarbônica de uma concentração de fragmentos de carvões situada no mesmo nível estratigráfico das gravuras, foi possível obter um intervalo cronológico de elaboração entre 7.840 BP a 7.600 BP (PESSIS, 2002); também no Parque Nacional da Serra da Capivara existe a informação (na parte externa do museu do Homem Americano) de outro sítio arqueológico, denominado Toca da Extrema II - Serra Branca, que por correlação sedimentar datada por $14 \mathrm{C}$, apresenta um bloco rochoso em arenito com gravuras que teriam sido elaboradas há, no mínimo, há 3.100 anos $\mathrm{BP}^{4}$.

No terraço aluvial do Rio Urubu, localizado no Estado do Amazonas, foram coletadas amostras de carvões que estavam em sedimentos que recobriam uma rocha com gravuras, cujas datações por $14 \mathrm{C}$ estipularam uma idade mínima entre $1110 \pm 30$ BP e $1170 \pm 30$ BP para a elaboração das gravuras, (CAVALLINI, 2014).

\section{As datações de gravuras rupestres pelo método da microerosão no Brasil.}

No ano de 2016 foi possível obter datações diretas com o método da microerosão em painéis gráficos de um conjunto de cinco sítios arqueológicos com gravuras rupestres, todos com suporte rochoso granítico, além da datação de um instrumento percutor utilizado na elaboração das gravuras em um sexto sítio

\footnotetext{
${ }^{4}$ Nota dos autores.
} 
(denominado sítio arqueológico da Descoberta, todos localizados no Estado do

Rio Grande do Norte, região do Nordeste do Brasil, conforme quadro 1 e figura 4;

\begin{tabular}{|l|l|l|l|l|}
\hline $\mathrm{N}^{\circ}$ & Sítio Arqueológico & Município & Microrregião & Estado \\
\hline 1 & Açude das Flores III & Afonso Bezerra & Angicos & RN \\
\hline 2 & Serra do Papagaio III & Santana do Matos & Serra de Santana & RN \\
\hline 3 & Santa Cruz & Angicos & Angicos & RN \\
\hline 4 & Pedra Pintada & Caraúbas & Chapada do Apodi & RN \\
\hline 5 & Serrote do Urubu & Pedro Avelino & Angicos & RN \\
\hline 6 & Descoberta & Fernando Pedroza & Angicos & RN \\
\hline
\end{tabular}

Quadro 1 - Relação dos sítios arqueológicos da pesquisa com o método da datação direta (microerosão) de gravuras rupestres no Nordeste do Brasil. Fonte: Santos Júnior, 2016, p.24.

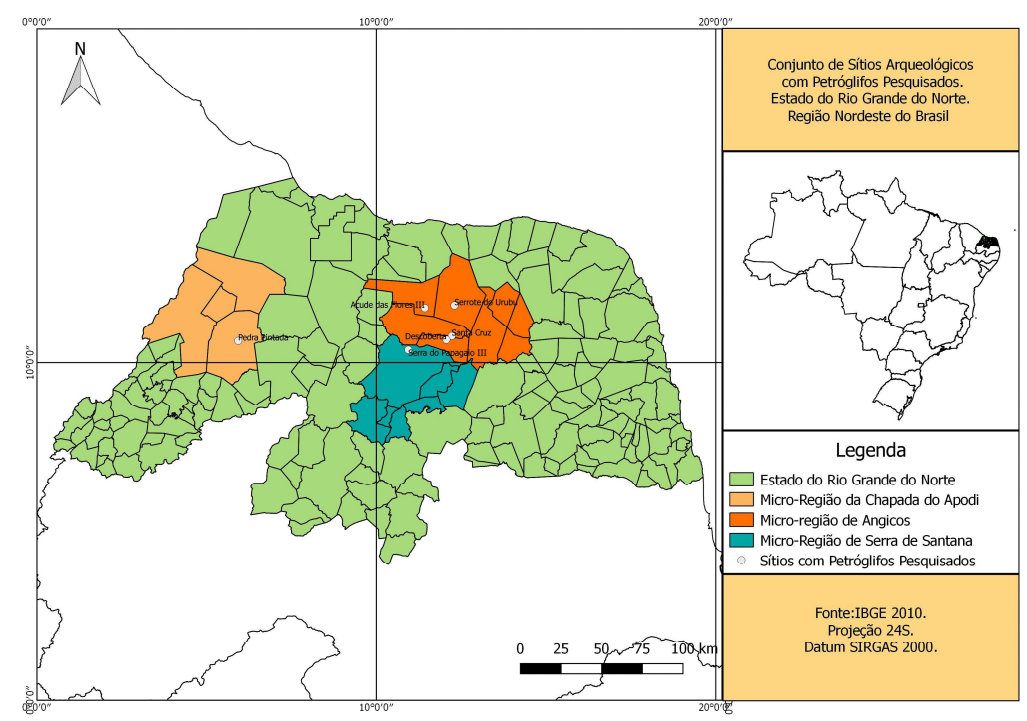

Figura 4 - Mapa de localização geográfica do conjunto de sítios arqueológicos datado com a utilização do método direto de microerosão das gravuras rupestres no Estado do Rio Grande do Norte - Nordeste do Brasil. Fonte: Santos Júnior, 2016, p.25. 
O quadro cronológico de dezessete datações diretas obtidas nas gravuras rupestres nos seis sítios arqueológicos pesquisados apresentou a composição, conforme tabela 1 .

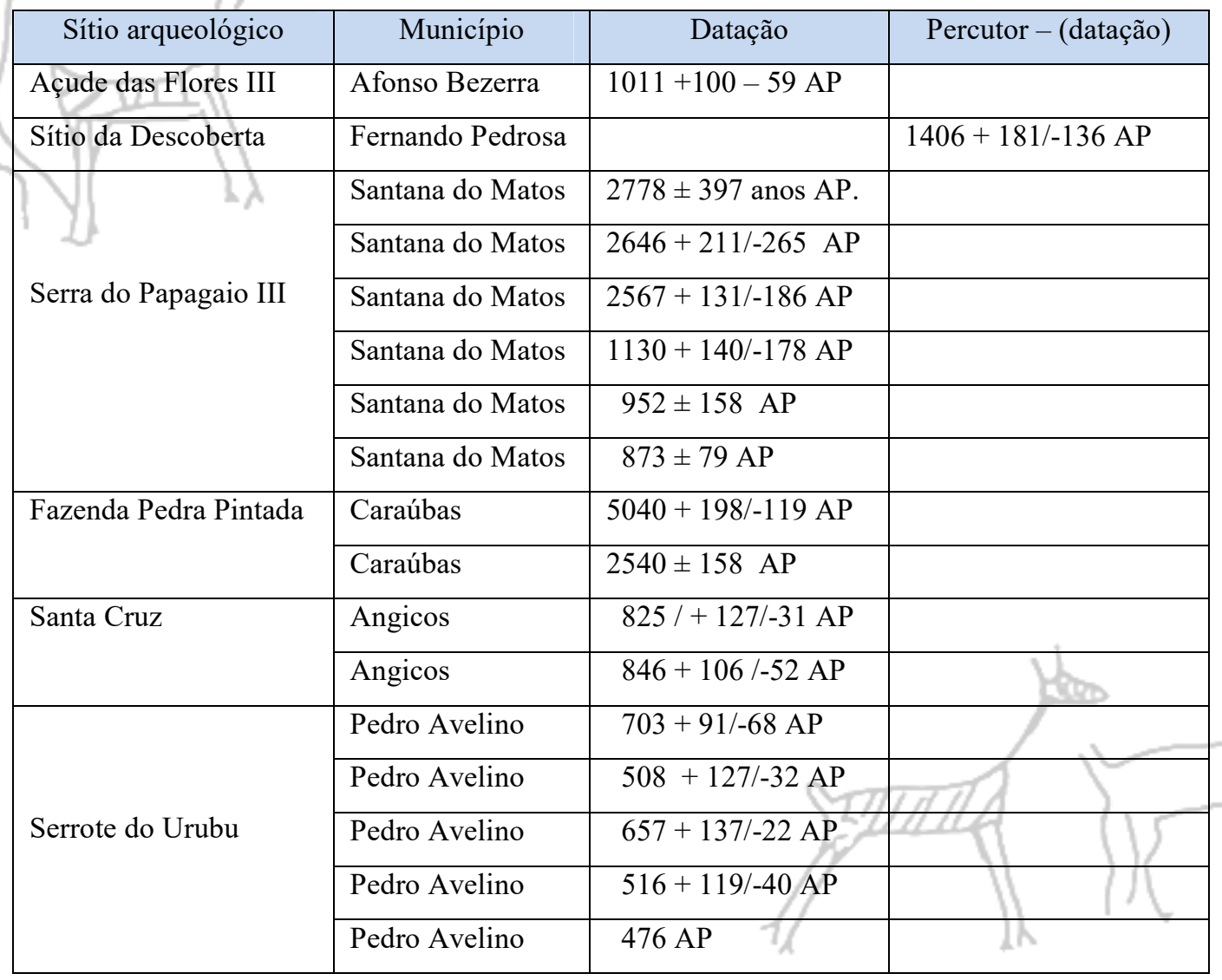

Tabela 1 - Datações das gravuras rupestres pelo método direto da microerosão no estado do Rio Grande do Norte. Fonte: Santos Júnior; Valle; Lavalle; Oliveira e Bednarik, 2018, p.94. 
Esse quadro de datações diretas das gravuras pelo método da microerosão sinalizam para atividades de elaboração do simbolismo rupestre com essa técnica entre 5040 + 198/-119 AP (datação mais antiga) e 476 AP (datação mais recente). Mesmo levando-se em conta as margens de erros, perfeitamente naturais diante de um conjunto de métodos (microerosão) criado relativamente recente (1992) e que necessita primordialmente da acuidade visual do observador na análise do intemperismo sofrido nas variações angulares das partículas de quartzo ou mica, existentes nos suportes graníticos, o que por si só, já é um fator limitante, mas a inclusão desse intervalo temporal de realização das gravuras está plenamente condizente com o contexto arqueológico da presença holocênica de grupos humanos na região, (tabela 2).

Ao analisar as datações diretas obtidas nas cúpulas do sítio Serra do Papagaio III, por exemplo, foi observada uma persistência temporal na elaboração somente dessa tipologia (representações cupuliformes) de gravuras que abrange o período entre $2.778 \pm 397$ AP (datação mais antiga) e $873 \pm 79$ AP (datação mais recente), com dimensões e pátinas variáveis nas cúpulas, evidenciando uma atividade recorrente por 1.905 anos (sem contar as margens de erro) e, possivelmente, com uma significação simbólica relevante para as diversas gerações de seus autores. 


\begin{tabular}{|c|c|c|c|c|}
\hline \multirow{2}{*}{ Microrregião } & \multirow{2}{*}{ Município } & \multirow{2}{*}{ Sítio arqueológico } & \multicolumn{2}{|c|}{ Datações } \\
\hline & & & $\begin{array}{l}\text { Ocupação mais } \\
\text { recente }\end{array}$ & $\begin{array}{c}\text { Ocupação mais } \\
\text { antiga }\end{array}$ \\
\hline Angicos & Angicos & Angico & $505 \mathrm{BP}$ & $9.000 \mathrm{BP}$ \\
\hline Angicos & $\begin{array}{l}\text { Caiçara do Rio do } \\
\text { Ventos }\end{array}$ & Pedra do Balcão & $-\mathrm{x}-$ & $10.270 \mathrm{BP}$ \\
\hline Angicos & Pedro Avelino & $\begin{array}{l}\text { Serrote dos } \\
\text { Caboclos }\end{array}$ & $1.000 \mathrm{BP}$ & $-\mathrm{x}-$ \\
\hline Assu & Assu/Macau & $\begin{array}{c}\text { Delta do rio } \\
\text { Piranhas/Assu }\end{array}$ & $980 \mathrm{BP}$ & $3.380 \mathrm{BP}$ \\
\hline $\begin{array}{l}\text { Seridó } \\
\text { Oriental }\end{array}$ & $\begin{array}{l}\text { Carnaúba dos } \\
\text { Dantas }\end{array}$ & Pedra do Alexandre & $1.000 \mathrm{BP}$ & $9.410 \mathrm{BP}$ \\
\hline $\begin{array}{l}\text { Seridó } \\
\text { Oriental }\end{array}$ & $\begin{array}{c}\text { Carnaúba dos } \\
\text { Dantas }\end{array}$ & Casa Santa & $479 \mathrm{BP}$ & $-\mathrm{x}-$ \\
\hline
\end{tabular}

Tabela 2 - Datações obtidas em escavações arqueológicas no Rio Grande do Norte. Fonte: Santos Júnior, 2016, p.84.

Outra característica que foi observada com a pesquisa foi a possível reutilização de gravuras efetuada por grupos pretéritos com práticas de "reavivamento" por grupos posteriores, como forma de perpetuação do simbolismo. Essa prática foi detectada no sítio "Serrote do Urubu" que teve um intervalo de datações entre 703 \pm 91/-68 AP (datação mais antiga) e $508 \pm 127 /$-32 AP (datação mais recente), sendo possível detectar duas gerações de gravuras com pátinas diferenciadas na mesma elaboração simbólica, ou seja, foi efetuada/uma primeira elaboração simbólica e, posteriormente, essa mesma elaboração simbólica foi retrabalhada, possivelmente entre 150 a 300 anos depois de sua criação inicial, mantendo a 
mesma morfologia das gravuras. Essa prática de reutilização já foi observada em outros sítios arqueológicos do Nordeste do Brasil:

\begin{abstract}
"O resultado final expressa a mesma percepção de Horror Vacui com a qual a arqueóloga Gabriela Martin definiu anos atrás o denso sítio rupestre com petróglifos da Pedra do Inga, no estado da Paraíba. A parede NE expressa um complexo palimpsesto diacrônico de usos e reusos, provavelmente milenares, performados possivelmente por distintos sistemas culturais e cosmológicos, para os quais a permanente ação de gravar distintas formas naquela mesma superfície rochosa, por cima das marcas anteriores, se configurava como um processo culturalmente significativo, resultando na alta densidade de preenchimento do espaço gráfico definível pela expressão Horror Vacui”, (MARTIN 1999), (VALLE, 2017, p.23).
\end{abstract}

A datação de $1406 \pm 181 /-136$ AP obtida para o percutor lítico localizado no sítio arqueológico da Descoberta, além de estar perfeitamente dentro do contexto cronológico de ocupação pretérita da microrregião de Angicos, abre uma nova perspectiva de pesquisa no cenário da arqueologia brasileira: investigar com métodos de datação direta os percutores utilizados na elaboração das gravuras rupestres para tentar efetuar possíveis dados comparativos entre a criação simbólica e os instrumentos utilizados pelos grupos do passado.

\title{
CONCLUSÕES
}

Conforme observado nesse artigo, as datações de gravuras rupestres obtidas por métodos diretos ou indiretos no Brasil, por diversos pesquisadores, indicam 
ocupações holocênicas que variam entre $476 \mathrm{AP}$ a $11.760 \mathrm{BP}^{5}$, ressalvadas as margens de erros. A obtenção desses dados cronológicos a partir da técnica de elaboração das gravuras rupestres vem somar aos dados temporais já obtidos com as datações oriundas dos registros picturais e auxiliando no entendimento dos processos de ocupações pré-coloniais do atual solo brasileiro.

Nesse sentido, tem sido observado um número mais frequente de datações de gravuras rupestres por métodos indiretos por pesquisadores brasileiros nos últimos anos, (VALLE, 2017; NEVES et al, 2012; CAVALLINI, 2014; PESSIS, 2002); já as pesquisas envolvendo aperfeiçoamento/criação de métodos de datações diretas das gravuras rupestres ainda são bastante recentes e geralmente efetuadas por pesquisadores de outros países, (BEDNARIK, 1992; WATCHMAN; 2000; DORN, 2004), mas já começaram a ser feitas também no Brasil (SANTOS JÚNIOR, Valdeci; VALLE, Raoni; LAVALLE, Henry; OLIVEIRA, Daline Lima, Oliveira and BEDNARIK, Robert G, 2018).

A quase inexistência de pesquisadores/arqueólogos que se dediquem mais especificamente aos estudos das gravuras rupestres no Brasil é um fator limitante, principalmente com relação à ausência total de pesquisas científicas (publicadas) com arqueologia experimental de gravuras em solo brasileiro. Penso que se

\footnotetext{
${ }^{5}$ Essa diferenciação entre AP (antes do presente) e BP (before presente) tem a ver com o método de datação utilizado; no caso da datação $476 \mathrm{AP}$ foi utilizado o método direto da microerosão que considera a contagem do período a partir da data atual (contemporânea) em relação à gênese da criação simbólica (gravuras); no caso da datação 11.760 BP foi utilizado método de datação indireto dos acréscimos sedimentares.
} 
continuar essa ausência de pesquisas, principalmente voltadas para a arqueologia experimental, ainda continuaremos por muito tempo dependendo de eventuais e raras datações indiretas para obter cronologias dos registros gravados.

As pesquisas científicas efetuadas em solo brasileiro em busca de cronologias dos registros gravados são raras tentativas de palmilhar por um caminho aparentemente difícil, mas que pode revelar, em futuro não tão distante, datações de gravuras bem mais antigas que as criações picturais (e isso não me causaria nenhum surpresa), auxiliando a entender o contexto dos processos das ocupações de grupos humanos pretéritos dos períodos colonial e pré-colonial no Brasil.

\section{REFERÊNCIAS BIBLIOGRÁFICAS}

ANATI, Emanuele. Valcamonica rock art: a new history for Europe. Londres: Study Camoni,1994.

BEDNARIK, Robert G. "The dating of rock art" in Bednarik, Robert (ed) Rock art science the scientific study of paleoart. New Delhi, Aryan Books International, pp. 115152, 2007.

. The Dating of Rock Art: a Critique. Journal of Archaeological Science. V. 29, p.1-20, 2002. 2001.

. Petroglyphs in Italian Alps dated. Acta Archaeologica. V. 72(2), p.109-114,

Age estimates for the petroglyph sequence of Inca Huasi, Mizque, Bolivia. Andean Past: Vol. 6, Article 13, 2000.

Analyses of Côa Valley petroglyphs. in International Rock Art Congress. Turim, Italy: IFRAO, 1995. 
A new method to date petroglyphs. Archaometry. V. 34 (2), p. 279-291, 1992.

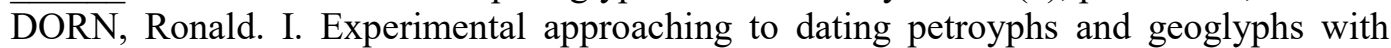
rock varnish in the California Deserts: current status and future directions. Mutarango Museum Publications. V.15, p. 211-224, 2004.

. Rock art dating. Section on Rock Art Dating In (ed) Archaeological Method and Theory: An Encyclopedia. London: L. Ellis, 2000.

. Constraining the age of the Côa Valley (Portugal) engravings with radiocarbon dating”. Revista Antiquity, V. 71, p.105-115, 1997.

CAVALLINI, Marta S. As gravuras rupestres da bacia do baixo rio Urubu: levantamento e análise gráfica do sítio Caretas, Itacoatiaras - Estado do Amazonas. Uma proposta de contextualização. Dissertação de mestrado em arqueologia, Universidade de São Paulo, 2014 .

COMMERLATO, Fabiana. As representações rupestres do litoral de Santa Catarina. Tese de doutorado. Pontifícia Universidade Católica do Rio Grande do Sul, 2005.

DUMONT, Jean F.; SANTANA, Essy M.; AZHAR, Hussin.; JOMELLI, Vincent. "Aplicaciones y limitaciones de las dataciones com líquenometría de morfologias costeras en Isla.

Greenwich", $<$ https://www.researchgate.net/publication/255822252_Aplicaciones_y_limit aciones_de_las_dataciones_con_liquenometria> (acessado em $12^{-}$de Abril de 2019), 2013.

ETCHEVARNE, Carlos. Escrito na pedra: cor, forma e movimento nos grafismo rupestres da Bahia. Rio de Janeiro: Organização Odebrecht, 2007.

FOSSATI, Angelo. Cronologia ed interpretazione. In Arcà A., Fossati A., Marchi E., Tognoni E., Rupe Magna (eds) La roccia incisa più grande delle Alpi. Sondrio: pp. 99$109,1995$.

GUIDON, Niéde; PESSIS, Anne-Marie. Ars Indígena Pré-histórica do Brasil. Revista Clio. $\mathrm{n}^{\circ}$ 14, p.135-141, 2000.

JIN A., ZHANG J., XIAO B. and TANG H. Microerosion dating of Xianju petroglyphs, Zhejiang Province, China. Rock Art Research 33(1): 3-7, 2016. 
LAGE, Welington. Por entre rochedos bordados passa um rio: um olhar da Gestalt para efetuar uma leitura do passado. Tese de doutorado, Faculdade de Letras da Universidade de Coimbra, Centro de Estudos em Arqueologia, Artes e Ciências do Patrimônio. 321 p, 2018.

- As gravuras rupestres do sítio bebidinha, Buriti dos Montes - Piauí: documentação, análise da linguagem visual e levantamento sobre o estado geral de conservação. Dissertação de mestrado em arqueologia. Universidade Federal do Piauí, 2013.

MAIA, Luís P.; GASTÃO, F. G. C.; TATUMI, S. H.; LACERDA, L. D. “A utilização do método de Luminescência Opticamente Estimulada para a datação de sedimentos de dunas costeira do nordeste setentrional do Brasil". Revista Virtual de Química. 3 (2), p.103-115, 2011.

MARTIN, Gabriela. Pré-história do Nordeste do Brasil. Recife: UFPE, 1997.

NEVES, Walter A.; ARAÚJO, Astolfo G. M.; Bernardo, DANILO V.; KIPNIS, Renato.; FEATHERS, James K. Rock Art at the Pleistocene/Holocene Boundary in PLOS ONE (ed) Eastern South America. San Francisco: PLOS ONE 7(2), p.1-5, 2012.

PESSIS, Anne Marie. Imagens da pré-história. São Paulo: FUNDHAM/PETROBRÁS, 2003.

. Do estudo das gravuras rupestres pré-históricas no Nordeste do Brasil. Revista Clio arqueológica, $\mathrm{n}^{\mathrm{o}}$ 1, p. 29-44, 2002.

PROUS, André. Arte rupestre brasileira: uma tentativa de classificação. Revista de PréHistória. $n^{\text {o }} 7$ p.9-33, (1989a).

. Las tentativas de datación de las obras de arte rupestre. Boletin de la Sociedad de Investigación del Arte Rupestre de Bolivia. v. 3, p.19-29, (1989b).

SANTOS JÚNIOR, Valdeci. Datações diretas de petróglifos no Nordeste do Brasil. Relatório de pesquisa de pós-doutorado, Faculdade de Letras da Universidade de Coimbra, Centro de Estudos em Arqueologia, Artes e Ciências do Patrimônio. 98 p, 2016. 
SANTOS JÚNIOR, Valdeci; VALLE, Raoni; LAVALLE, Henry; OLIVEIRA, Daline Lima, Oliveira and BEDNARIK, Robert G. Direct dating of petroglyphs in Rio Grande do Norte, Brazil. Rock Art Research - Volume 35, Number 1, pp. 85-97, 2018.

SOARES, Antônio. M. M. Os métodos de "datação directa" aplicados no Côa. In: Primeiro Congresso de Arqueologia Peninsular. Porto 12 a 18 de outubro de 1993. Porto: Sociedade Portuguesa de Antropologia e Etnologia, 1995.

TANG H., G. KUMAR, Liu W., XIAO B., YANG H., ZHANG J., Lu X. H., Yue J., Li Y., GAO W. and R. G. BEDNARIK. The 2014 microerosion dating project in China. Rock Art Research 34(1): 40-54, 2017.

VALLE, Bernardo M. R. Valle, R. B. M. Relatório técnico final. Projeto Pedra do Sol: contextualização arqueológica e datação relativa de gravuras rupestres na Amazônia Brasileira, Roraima. Ufopa, Cnpq, Iphan. Santarém, Pará, 2017.

- Mentes graníticas e mentes areníticas: fronteira geo-cognitiva nas gravuras rupestres do baixo Rio Negro, Amazônia Setentrional. Tese de doutorado. Universidade de São Paulo, 2012.

WATCHMAN, Alan. "A review of the history of dating rock varnishes". Earth-science reviews. $\mathrm{N}^{\mathrm{o}} 49$, p.261-277. 2000.

1995.

. Recent petroglyphs, Foz Côa, Portugal. Rock Art Research 12(2): 104-108.

WHITLEY, David S; LOENDORF, Larry L. "Rock art analysis" In Herbert D.G M. and Christopher C. (eds) Handbook of archaeological methods/edited by. Maryland: Altamira Press, pp. 919-973. 2005.

ZILHÃO, João. "Public archaeology and political dynamics in Portugal A reply to Bednarik”. Public archaeology. V. 3, p.167-183.2004.

. The stylistically paleolithic petroglyphs of the Côa Valley (Portugal) are of Paleolithic Age. A refutation of their "direct dating" to recent times". in Primeiro Congresso de Arqueologia Peninsular. Porto 12 a 18 de outubro de 1993. Porto: Sociedade Portuguesa de Antropologia e Etnologia, 1995. 